\title{
MINAS: UMA ANÁLISE DA FORMAÇÃO IDENTITÁRIA E CULTURAL DO ESTADO DO OURO
}

\section{MINAS: AN ANALYSIS OF THE IDANTITARY AND CULTURAL FORMATION OF THE STATE OF GOLD}

Steven Adrian dos Santos*

\begin{abstract}
RESUMO
Esta pesquisa deflagra a ordem social do Estado de Minas Gerais no período compreendido entre os anos de 1692 a 1789. Respectivamente, da descoberta do ouro até a Inconfidência Mineira. Tem por meta entender o sentido da independência de que tanto falam os autores e cantam os poetas. Analisa-se o cenário geológico como base propedêutica para compreensão da história das jazidas. Examina-se o modus operandi da administração portuguesa no Brasil. Busca-se desvendar a cultura mineira sob os enredos dos poetas, dos eventos e acontecimentos que cercam e dão consistência à história das Minas do Ouro. Elucida-se um novo sentido para a "independência", desta vez, para lá de política.

Palavras-chave: Formação. Minas Gerais. Cultura. Ouro.
\end{abstract}

\begin{abstract}
This research triggers the social order of the State of Minas Gerais, which does not cover a period between the years 1692 and 1789. Respectively, from the discovery of gold to the Inconfidência Mineira. Its aim is to feel the sense of independence of which authors speak and poets sing so much. The geological scenario is analyzed as a propaedeutic basis for understanding the history of the deposits. The modus operandi of the Portuguese administration in Brazil is examined. It seeks to unveil the culture of Minas Gerais under the plots of poets, events and events that surround and give consistency to the history of Minas do Ouro. A new meaning for independence is elucidated, this time, beyond politics.
\end{abstract}

Keywords: Formation. Minas Gerais. Culture. Gold.

\section{CONSIDERAÇÕES INICIAIS}

Mostrando os montes, dizia Que isto é terra sem igual, Que debaixo destes pastos É tudo rico em metal... (MEIRELLES, 1997, p.97)

Poucos autores se aventuraram na complexidade dos relatos humanos como os poetas mineiros; uns experimentaram a narrativa ficcional para satirizar e denunciar as desventuras da

Artigo submetido em 21 de julho de 2021 e aprovado em 10 de setembro de 2021.

* Graduando em Direito pela Pontifícia Universidade Católica de Minas Gerais. E-mail: steveaadrian.santos@gmail.com. 
província; outros relataram e idealizaram o sentimento popular, as desordens e as fragilidades das relações humanas. Enquanto decodificadores do imaginário social, autores e poetas traduziram o comportamento humano e possibilitaram a linha de raciocínio que aqui se desenvolve. Entende-se que a literatura é a principal ferramenta de transmissão de cultura, é a narrativa dos povos, a construção relatada de sua identidade. A literatura é, antes de tudo, a antecipação dos acontecimentos (CARPEAUX, 2012), e os seus agentes, os literatos, são tradutores do imaginário humano. Assim se faz a história; do resultado de um processo dialético que consiste no antagonismo de elementos culturais, econômicos e da organização social. Das narrativas e das transmissões de cultura. Duas ideias opostas são suficientes para formar uma nova estrutura da realidade e determinar o

modo do homem comportar (VÁZQUES, 2007, p.37). A moral da sociedade mineira corresponde às suas características materiais de produção, de propriedade e de posse, e, corresponde também, àqueles atributos imateriais; os costumes, os valores morais e espirituais. Relata-se uma história atormentada pela riqueza mineral e pelas complexas relações humanas que tinham por objeto o enriquecimento. Nesta linha, equivocou-se o polímata Otto Maria Carpeaux, porque na verdade a literatura brasileira pré-modernista teve sim raízes na vida da nação, sobretudo, a mineira (CARPEAUX, 2012, p.149). Seja nas narrativas de Cecília Meireles, ao nos trazer os fatos da inconfidência em seu $O$ Romanceiro da Inconfidência, ou nos infortúnios administrativos relatados por Tomás Antônio Gonzaga, em suas Cartas Chilenas. Seja na literatura crítica de Bartolomeu Campos de Queirós nas Minerações e Literatura Juvenil, nas precípuas declarações de Carlos Drummond de Andrade e o seu Alguma poesia, ou José Maria Quintão $e$ a história da cidade de Ferros em Aquidabam, Ponte e Vau (no ontem e no hoje de Ferros), ou , por fim, no anseio por civilizaçãopresente na peça de Quintino Bocayuva, Os Mineiros da Desgraça. Há uma identidade incessantemente buscada, dentro dela, uma ordem social e cultural buscada e explicitada por esta pesquisa.

\section{METODOLOGIA}

A investigação tem cunho teórico e se trata de uma revisão bibliográfica. Analisa-se diversos gêneros literários com intuito de traduzir os acontecimentos pela narrativa direta dos contemporâneos e extemporâneos.

\section{CENÁRIO GEOLÓGICO}

Dedica-se especial atenção à morfogenia mineira. Uma fortaleza natural cujo maciço território se revela tão afeito à vida (CUNHA, 1984, p. 4). Não era o europeu afeito à visão paradisíaca das terras de Santa Cruz aludida pelos contos místicos da sociedade europeia (VERGUEIRO, 1981, p.7) e, tampouco, preparado para as riquezas de Minas.

O território que marca as delimitações do atual Estado de Minas Gerais é composto de acidentes geológicos conhecidos mundialmente por sua geodiversidade e riqueza mineral (ALKMIN, 2018). Trata-se de planalto montanhoso que replica a mesma formação de todo o território brasileiro não-amazônico, "desce, nos litoraisdo Sul, em escarpas inteiriças, altas e abruptas. Assoberba os mares; e desata-se em chapadões nivelados pelos visos das cordilheiras maritimas, distendidas do Rio Grande a Minas" (CUNHA, 1984, p. 1). De um extremo a outro, do Espirito Santo ao Paraná, o continente exibe ao oceano uma barreira de montanhas, a princípio, inóspitas (MAXWELL, 1973, p. 108).

Data-se a maior parte do território do período Pré-Cambriano, compreendido desde a formação da terra até o início do Cambriano. Ergueu-se, no Pré-Cambriano, o bloco continental do São Francisco. É neste cráton que o Quadrilátero Ferrífero (FIGURA 1) se encontra com efetiva riqueza mineral. Acham-se nesta formação geológica aquelas jazidas das quais a Corrida 
do Ouro se embebedou. O bloco é responsável por $40 \%$ do ouro produzido no Brasil. A partir do mapeamento geológico de 1950 a 1960, mostra-se forte concentração mineral em 4 supergrupos. Nota-se riqueza mineral até a fronteira com São Paulo, no Complexo de Poços de Caldas (ALKIMIN. 2018, p. 21). A concentração orogênica e mineralizada se encontra nos grandes distritos de ouro e ferro, como é o caso do Supergrupo Minas que detém grande faixa de Ouro Preto a Santa Rita Durão; caso também de Jacutinga, com extensa faixa mineralizada, de Mariana até Itabira. Igualmente se identifica o metaconglomerado da região da Moeda com depósitos de ouro (ALKIMIN, 2018, p. 14). Além do Supergrupo Rio das Velhas, onde se localizam os grupos Maquiné, Nova Lima e Quebra-osso.

\section{FIGURA 1: Mapa do Quadrilátero Ferrífero; Mapa geológico de Minas Gerais.}

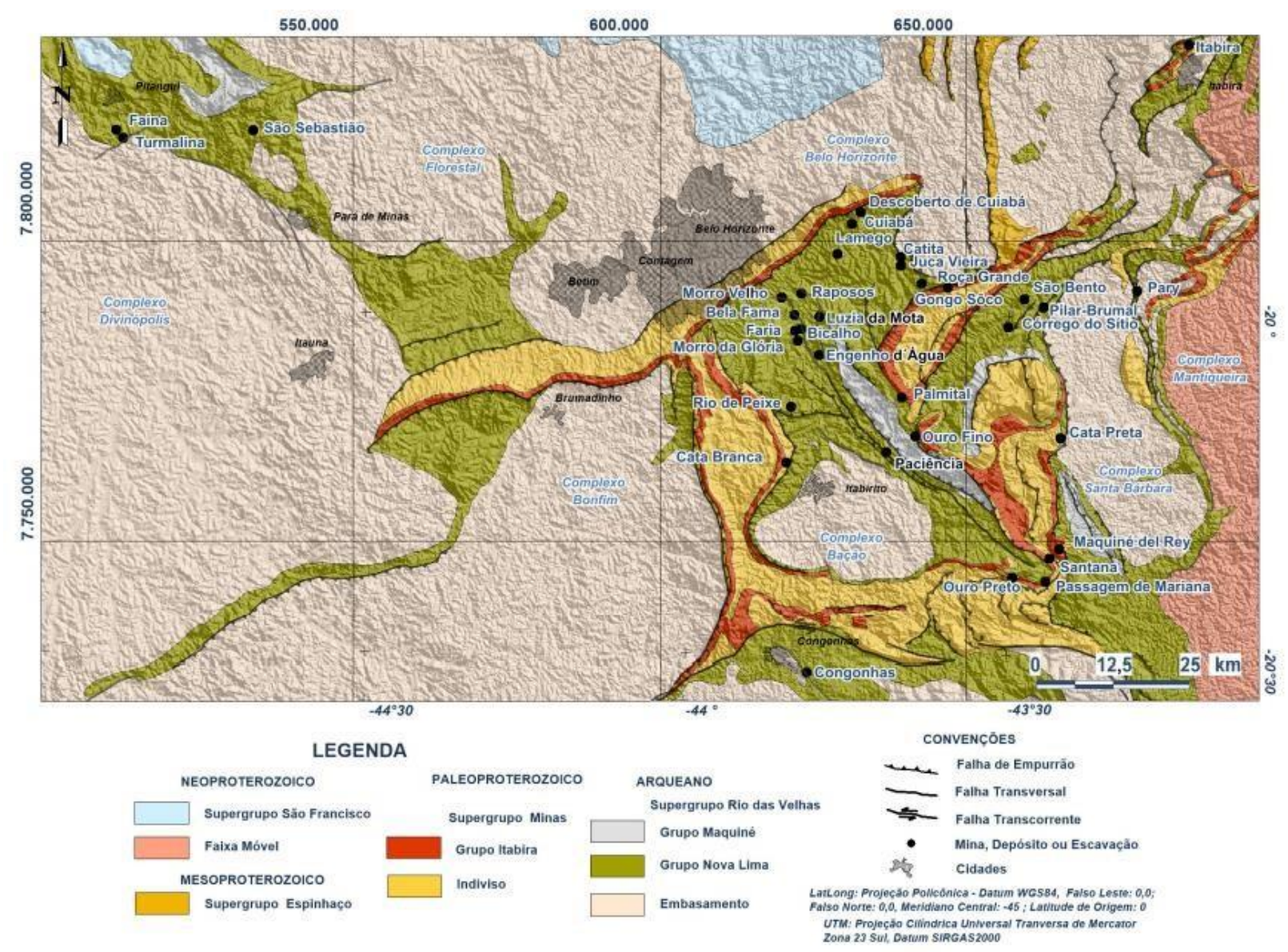

FONTE: LYDIA, Maria Lobato \& COSTA, Marco Aurélio da. Recursos Minerais no Cenário

Geológico de Minas Gerais. Belo Horizonte; Universidade Federal de Minas Gerais.

\section{MINAS GERAIS DE OURO}

Não pensara o bandeirante João Leite da Silva Ortiz que sua fazenda estabeleceria o arraial Curral del-Rei e, a posteriori, Belo Horizonte ${ }^{11}$, a capital de Minas Gerais ${ }^{22}$. Muito pelo contrário, a formação de Minas não decorreu do povoamento casuístico de alguns bandeirantes. Está no seu processo de formação o anseio por pedras e metais preciosos, ambição que arrastou

\footnotetext{
${ }^{1}$ Decreto 36 de 12/04/1890.

${ }^{2}$ Decreto 36 de 12/04/1890.
} 
bandeirantes por toda a América do Sul. Dentre as bandeiras, a que mais se destacou foi aquela responsável pelo achamento das Minas Gerais. Até o século XVII as missões já alcançavam toda a América do Sul, mas poucas delas chegaram ao planalto montanhoso que hoje chamamos de Minas Gerais. Primeiro pela dificuldade de acesso e segundo pela inexistência de escravos para apresamento (AMARAL, 2012, p. 7). O percursor do adentramento desta fortaleza natural montanhosa foi Fernão Dias, a quem se deve o nome da Rodovia que liga hoje os Estados de Minas Gerais e São Paulo. No insucesso de encontrar as tais preciosas pedras e metais, Fernão Dias morreu antes que retornasse à São Paulo, ascendendo ao poder o seu genro, Manuel de Borba Gato, até 1708, quando derrotado pela chamada guerra dos emboabas (VASCONCELOS, 1904, p. 37).

Foi Borba Gato quem descobriu o ouro, anunciando-se em 1692 que, no Rio Casca, afluente do Rio das Velhas, na bacia do Rio São Francisco, o Ouro Preto fora revelado. Percebese uma formação provocada e desordenada. Desde então o fluxo de escavadores aumentou exponencialmente, nota-se que se em 1692 a população das regiões das minas era de centenas de colonos e habitantes, já em 1776, "excluídos os índios, era superior a 300 mil habitantes, $o$ que representava $20 \%$ da população total da América portuguesa e constituía a maior aglomeração da colônia" (MAXWELL, 1973, p.109). Torna-se, Minas Gerais, a maior concentração populacional do Brasil. Dessa forma aparece o cenário que permitiu o desenvolvimento da economia interna da colônia. No âmbito econômico se percebe a relação firmada entre a quantidade exorbitante de ouro e a intensa procura. $\mathrm{O}$ descompasso ofertaprocura que fomentou a inflação na Europa e no Brasil. Houve, concomitante, crise de fome, por falta de alimentos e serviços básicos, que é o caso da agricultura e pecuária. O povoamento dessas vilas, como consequência de uma mineração intensificada, acentuou a criminalidade, as mortes e a violência (VASCONCELOS, 1904, p.327). Uma convulsão de toda a sociedade. Cita Laura Vergueiro (1981, p.37); "D. Pedra de Almeida à corte: "a terra evapora tumultos, a água exala motins".

O descompasso existente entre este estabelecimento desorganizado e a ausência material de um poder reclamou à Coroa novas medidas, pois se tratava do governo das minas (EDNA, 2005, p.1). Enquanto agente de coesão moral, o governo português suscitou modificações profundas para o controle da sociedade, por meio da Igreja. Vê-se declarada intervenção naquele aparelho de alianças e parentescos (EDNA, 2005, p.2). Em seguida, deu causa às mudanças na arrecadação do fisco. De início atividade delegada aos bandeirantes, por serem as principais autoridades das Minas. Não apenas do ouro, mas também do diamante extraído, sobretudo, da emblemática Diamantina. Perpetuava na Coroa portuguesa a ideia de que as terras auríferas compactavam a mais abundante reserva de ouro. Convicção que hoje podemos apontar como equivocada, mas que levou-a cobrar impostos irracionais (AMARAL, 2012, p.15), dando causa, naturalmente, à atividade contrabandista. Nota- se que em pouco tempo o poder erguido pelo contrabando era maior do que o dos chefes vicentinos; os primeiros sinais da famosa Campanha dos Emboabas ${ }^{3}$, relata Cláudio Manuel da Costa (1839, p.11); "Por este tempo se começarão [a] suscitar os ódios entre os filhos de S. Paulo, e os naturaes de Portugal, que elles [denominavam] Buabas". Em breves esclarecimentos, a referida reclamação feita pelos bandeirantes contra os chamados forasteiros ${ }^{44}$ foi resultado do conflito de poderes decorrentes do desarranjo social atrelado à época. É neste episódio que Minas Gerais realmente nasce, sobretudo com a segregação das capitanias de São Paulo e Minas do Ouro em Capitania de São

\footnotetext{
${ }^{3} \mathrm{O}$ termo indica forasteiros (AMARAL, 2012, p. 17).

44 A mais precisa delimitação e compreensão da Guerra dos emboabas é a de que os bandeirantes, paulistas e conservadores, declararam-se contra os forasteiros, que nem sempre, mas na maioria das vezes, eram portugueses. Entretanto, relatos históricos mostram que o conflito era, na verdade, contra qualquer um que não os próprios bandeirantes, sobretudo no caso dos baianos, em condições análogas àquelas narradas por Graciliano Ramos, Vidas Secas, ou seja, fugindo da pobreza e da seca do nordeste
} 
Paulo e Capitania de Minas, em decorrência de Antônio de Albuquerque, responsável por apaziguar o conflito dos emboabas (ROMEIRO, 2010, p.171) e a quem Cláudio Manoel da Costa (1839, p.14).cantou elogios heroicos em Vila Rica, na exaltação; "Prostrarão-se aos pés de Albuquerque os rebeldes, e desculparão quanto lhe foi possível".

A desordem social resultava de um poder exercido paralelo à realidade. O governo português, do outro lado do Atlântico, não era, por óbvio, competente para as questões atinentes à ordem social. Na organização econômica a capitania mineira permaneceu bem-sucedida, no entanto a ordenação social e política estava em colapso, mesmo com a pacificação trazida por Albuquerque, outros levantes ocorreram. Caso do Motim de Pintaguy (VASCONCELOS, 1904, p.330). Há de se destacar também que o papel da Igreja igualmente se tornou instável, pois os "[...] clérigos recebiam do governo quantia referente a atividade [e destas] cobranças [sucediam] escândalos e processos eclesiásticos" (SAINT-HILAIRE, 1938, P.156). A separação das capitanias de São Paulo e Minas teve por intuito a regulamentação da receita, do quinto, a criação de taxas administrativas, bem como a repressão dos escândalos e abusos do clero (VASCONCELOS, 1904, p.204). Isto é, buscou-se a coesão social tal qual se tinha no Estado Português. Entretanto, as Minas não eram portuguesas, e o povo que lá se estabeleceu tinha em si este conhecimento.

Criou-se as três primeiras vilas; Vila do Carmo (Mariana), Vila Rica (Ouro Preto) e Vila de Sabará (CHAVES, 2013, p.9) (FIGURA 2).

Figura 2 - Capitania das Minas. Vilas Criadas (1711-1814)

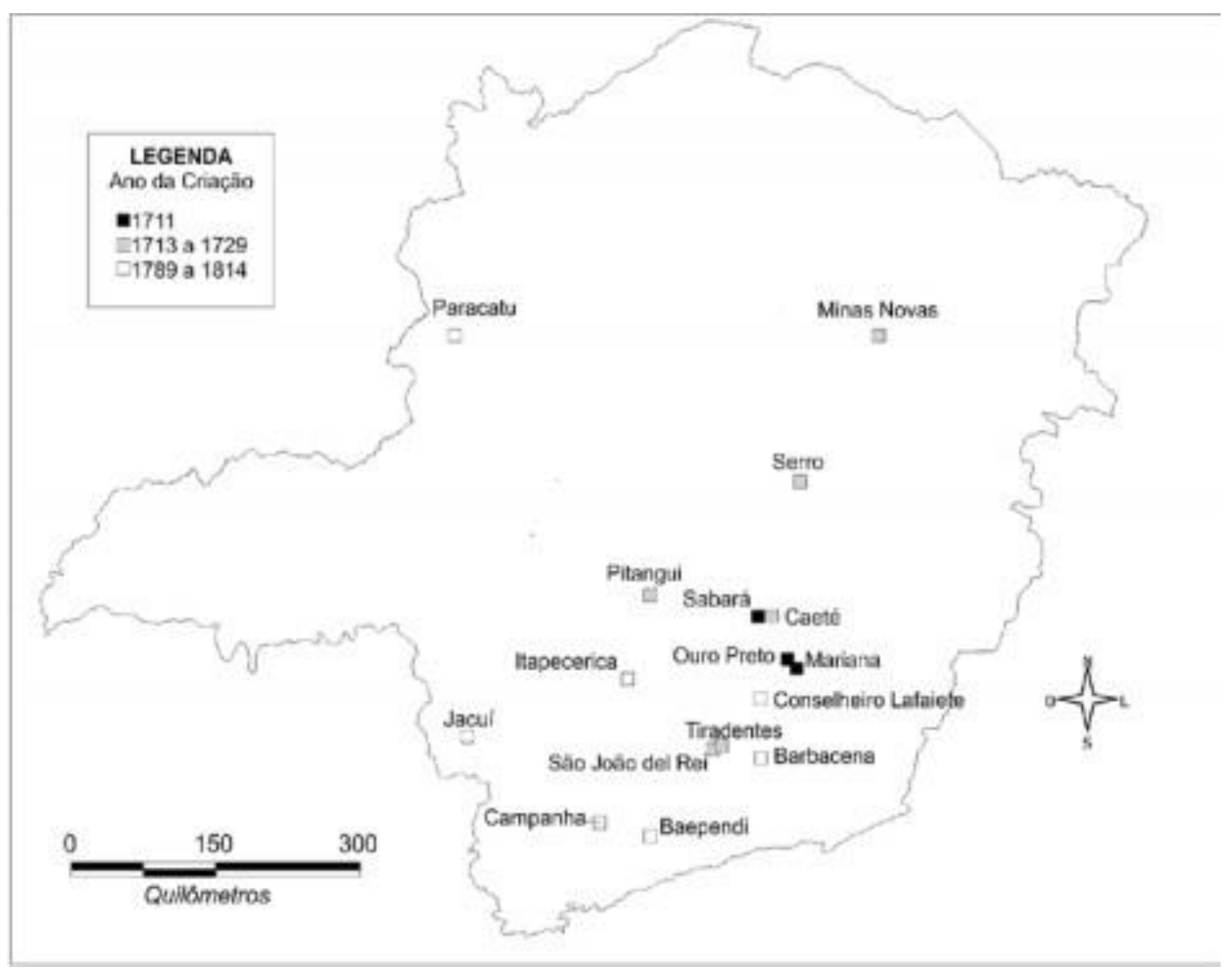

Fonte: REDE DE CIDADES EM MINAS GERAIS NO SÉCULO XIX. RODARTE, Mario Marcos Sampaio. PAULA, João Antonio de. SIMÕES, Rodrigo Ferreira.

Nesta rede de cidades estabeleceu-se a logística do ouro; uma arquitetura de escoamento 
aurífero que marcou profundamente a estrutura político-administrativa da província. Conforme se vê na FIGURA 3, privilegiou-se a dinâmica das minas; nas chamadas Estradas reais, que deu contorno a dezenas de municípios brasileiros. Identifica-se que a estrutura viária nas Minas se desenvolveu nestas Estradas Reais, levando o ouro de Minas para o mundo. Por outro lado, mais tarde, a estrutura ferroviária superou-a, marcando ainda mais as cidades; isto posto, vê-se nas cidades seus cartões postais que exaltam e recobram a época, casos de Moeda, Brumadinho e Juatuba.

\section{FIGURA 3: Mapa em branco do Estado de Minas Gerais considerando os fatores: rede viária e jazidas e minas.}
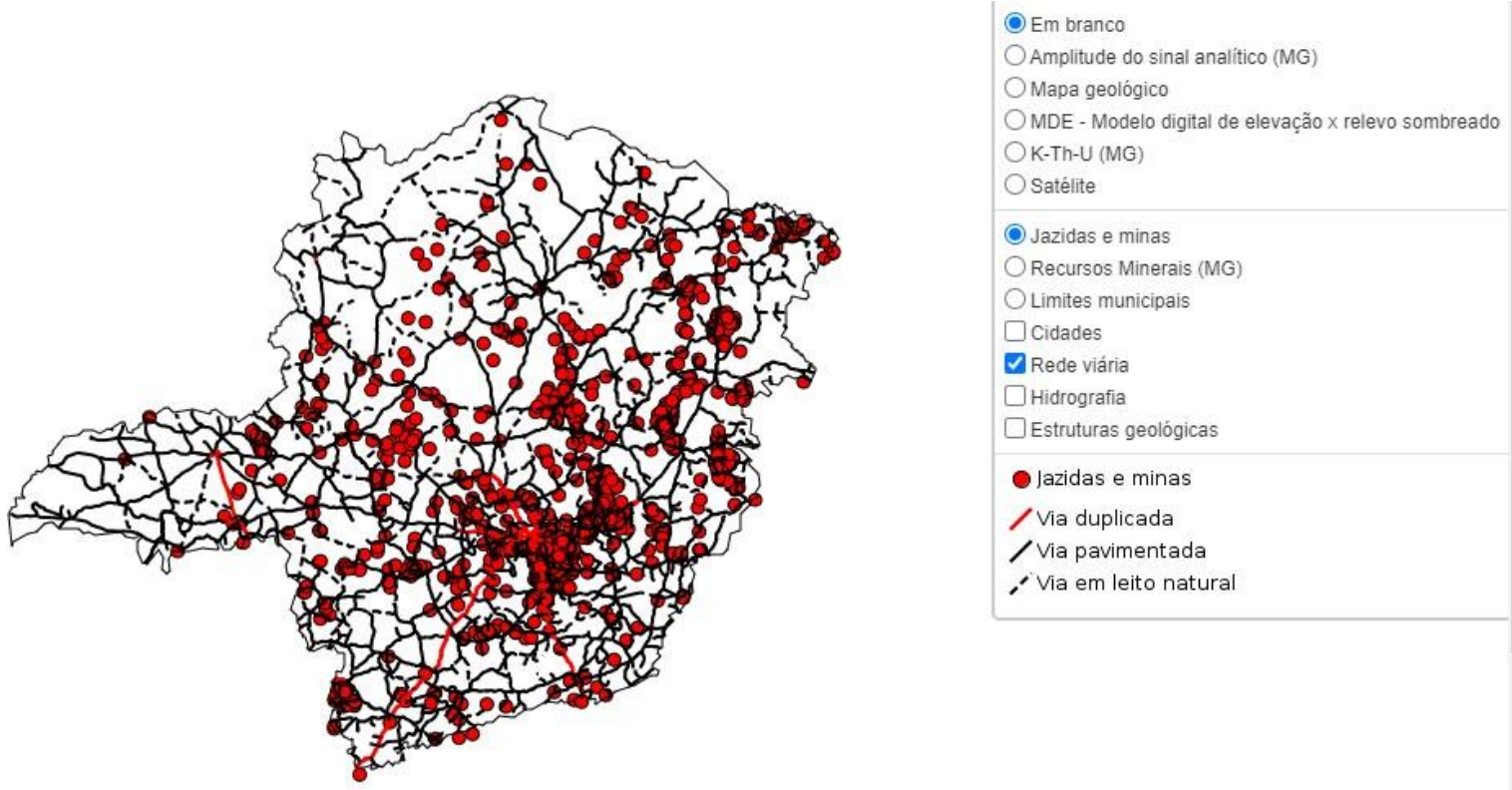

FONTE: Recursos Minerais de Minas Gerais (RMMG). Disponível em:

http://recursomineralmg.codemge.com.br/mapa/. Acesso em: 21 de setembro de 2020.

As mais sérias crises econômicas demoram a exibir sua gravidade (DORIA, 2013),

Diogo de Vasconcelos (1904, p.318) conta que a cobrança do tributo era “[...]mais bem aparelhad[a] [nas Minas] que em todas as outras capitanias[...]". Para a Coroa portuguesa as Minas Gerais se enriqueciam pelo ouro, quando na verdade o enriquecimento se dava pelo fluxo intenso e massificado de exploradores e viajantes. Embasada em tal premissa, estabeleceu medidas infelizes para o povoamento nas Minas: aumentou a cobrança tributária, irracionalmente, e propôs a unificação do escoamento aurífero nas "casas de fundição". De fato, adotou posicionamentos que foram em desencontro da atração e ascensão econômicas, portanto, na contramão do ritmo social até então visto. As casas de fundição foram instauradas pela Lei de 11 de fevereiro de 1719, contudo, tornaram-se um "espantalho" (VASCONCELOS, 1904, p.313). Sendo o quinto fixado, em 1720, em 37 arrobas, até 1734-1735, quando fixado em 100 arrobas. E, a partir de 1750, sob a influência de Marquês de Pombal, a Coroa demonstra intento de amistosa relação com a Colônia, quando substitui as Casas de Fundição pelo envio de 100 arrobas anuais. Assim narra Sebastião da Rocha Pitta;

[...] havendo também Sua Magestade attenção na mayoria do preço, que agora permitte à ventagem das arrobas, que os Mineiros accrescentarão ao tributo, que dá lavra deste metal the pagarão, em que aquelles súbditos não contribuírão com a importaricia dos quintos, que devem de direito à Real Fazenda, interessando elles a mayor parte do que pertence ao nosso Monarcha nos tesouros, que a natureza poz 
nesta Região, descuherta pelos Seus Vassallos, e dominada cio seu Augusto Sceptro. (PITTA, 1878, p.417).

Relata Tomás Antônio Gonzaga o descontentamento popular, com a baixa na extração do ouro e a cobrança do tributo;

155 - Ah! pobre Chile, que desgraça esperas! Quanto melhor te fora se sentisses As pragas, que no Egito se choraram, Do que veres que sobe ao teu governo Carrancudo casquilho, a quem rodeiam (GONZAGA, pág. 6)

Outro viés que traduz o sentimento;

E aí residia a questão: não era a pobreza dos pequenos mineradores que doía para a Metrópole, mas o fato de ser impossível aos homens pobres pagar os pesados tributos que deveriam seguir para o Reino e engordar a receita da Coroa portuguesa. (VERGUEIRO, 1981, p.33).

Assim, embora o governo exigisse o pagamento dos impostos; do quinto, das Entradas e o Dízimo, quase não prestava serviços, sendo que cada nova obra pública exigia um imposto próprio (DORIA, 2013). O contrabando, por conseguinte, aumentou exponencialmente; estava no desvio do ouro pela mata, na qual o exército adentrava frequentemente para combater (DORIA, 2013). A cobrança, por parte da Coroa, beirara as 100 arrobas anuais e, na hipótese do inadimplemento, enviar-se-ia dragões para cobrança da derrama, ou seja, a execução físcal dos atrasos. A falta de arrecadação gerara mais e mais endividamento entre os colonos. A Coroa, cética da baixa na extração, ameaçou a execução da derrama.

Se a derrama for lançada,

Há levante, com certeza. (MEIRELES, 1977, p. 80)

A dívida das Minas beirava as 600 arrobas, quase 600 toneladas de ouro (AMARAL, 2012, p. 48). Na iminência da cobrança do imposto e em encontros sigilosos, desencadeara a tentada Inconfidência Mineira. Nas palavras da poeta;

Tenha meus dedos cortados, antes que tal verso escrevam... LIBERDADE, AINDA QUE TARDE, ouve-se em redor da mesa. E a bandeira já está viva [...] já são réus, pois se atreveram a falar em liberdade (que ninguém sabe o que seja). (MEIRELES, 1977, p.81).

Um levante social dissolvido antes mesmo que se consumasse. Culminou na delação premiada de alguns dos envolvidos e no fim emblemático do mártir Tiradentes, a quem de se deve o dia 21 de abril.

Ó meio-dia confuso, Ó vinte-e-um de abril sinistro, Que intrigas de ouro e de sonho Houve em tua formação? Quem ordena, julga e pune? Quem é culpado e inocente? (MEIRELES, 1997, p.11) 
A dívida de certo não foi liquidada, pois coexistia uma máquina de recolhimento tributário falida e uma realidade orgânica distinta. Percebe-se que a excitação aurífera permitiu o crescimento da atividade latifundiária de plantation no litoral, o surto do ouro criara, pela primeira vez, um mercado a centenas de quilômetros da costa para produtos como cachaça e açúcar, até então apenas exportados (MAXWELL, 1973, p.110). As imbricações da atividade mineradora e a economia da Colônia não podem ser apontadas, com precisão, até os dias hoje, sabe-se que "O declínio de Vila Rica e a ascensão do sul refletiam a queda do papel dominante da mineração e a crescente importância das atividades agrícolas e pastoris" (MAXWELL, 1973, p.110).

Nos anos de 1692 até 1789 viu-se a constante migração para as Minas Gerais e o fracasso da organização social, como podemos observar, precipuamente, naquelas revoltas e motins. De fato, a atuação da Coroa na Colônia retardou o seu crescimento e independência, mas não obstou, seja pela autonomia intelectual marcada, sobretudo, após o enorme fluxo de viajantes, ou pelo enriquecimento material; a ampliação das relações sociais determinadas, a manufatura, a agricultura e a pecuária. Assim pontifica Laird W. Bergard (1999, p.43); "It is clear, however, that the mining centers provided a domestic market for dietary staple products and manufactured goods produced by Mineiro farmers, ranchers, and small-scalemanufacturing enterprises" 5 . Em nenhum lugar do mundo se viu um século encerrar- se com tantas prostitutas e crianças abandonadas como se fez em Minas. Os resultados da crise econômica se perpetuaram ainda mais no tempo, gerando, por consequência, a acentuação da pobreza e da violência (DORIA, 2013).

\section{EMANCIPAÇÃO DO OURO, DO DIAMANTE E DO MINÉRIO}

Dão causa à formação do Estado de Minas Gerais aqueles eventos registrados em sua construção desde a revelação do ouro preto. Suas riquezas, de início, reduziam-se ao ouro e ao metalismo, mas, com o transcorrer do tempo, os valores e os costumes do povo que ali se instalara logo comporiam, também, sua cultura. Considera-se também a esmagadora participação dos escravos em todos estes processos, tal qual, é fidedigna a análise que associa os seus autores ao sentimento de identidade fecundo desde o achamento das minas de ouro, assim como à matriz escravocrata. O Ciclo do Ouro absorveu mão de obra escrava em proporções inéditas (GALEANO, 1976). Ainda nos dias de hoje se verifica com facilidade que o elemento da "cultura de ferro" retorna aos enredos, narrativas e romances de uma sociedade castigada pelas veias expostas (GALEANO, 1976). De fato, os autores sonharam a independência de Minas muito além da separação política, mas também aquela do minério, do ouro, do diamante, que se fala tanto por Cecília Meireles, Euclides da Cunha, Cláudio Manuel da Costa, Tomáz Antônio Gonzaga, Carlos Drummond de Andrade, e aqueles que ainda hoje cantam e poetizam-na.

Há fases da formação cultural que refletem também na busca de uma identidade cultural. O primeiro momento é marcado pelo ouro. Pelo intercâmbio cultural de uma relação dialética que confronta valores e inaugura novos elementos da realidade. Com os tropeiros se funda Betim, com os bandeirantes se funda Belo Horizonte, Sabará, Mariana, São João del-Rei (...). O cartão postal das Minas: as Estradas Reais, aquele sistema que levaria o ouro preto para o mundo. A arquitetura mineira nos traços de Antônio Lisboa, o Aleijadinho. As "formosas igrejas no original estilo barroco [...] exteriormente [...] pareciam sóbrios, despojados, porém o interior, símbolo da alma divina, resplandecia no ouro puro dos altares[...]" (GALEANO,

\footnotetext{
5 "É claro, no entanto, que a mineralização fornecia um mercado interno para produtos de base alimentar e manufaturados produzidos por fazendeiros mineiros, pecuaristas e pequenas empresas manufatureiras". (Tradução nossa)
} 
1976, p.64).

Em um segundo momento, numa dimensão cultural posterior à euforia do ouro, os poetas e os escritores narram aqueles conflitos derivados da incoesa administração portuguesa e da urbanização desordenada. Esse momento é marcado pelos conflitos internos, os motins e as revoltas, um claro sinal de que já se fala dos sentimentos de liberdade e autonomia. O terceiro momento deriva desses sentimentos de modo que nada mais pode lhe traduzir do que: "liberdade, ainda que tardia". Trata-se do resultado de um complexo sistema moral que antagonizou o domínio português e a elite mineira.

\section{CONSIDERAÇÕES FINAIS}

A história de Minas Gerais é a história do Brasil. Tal qual algum dia bandeirantes se aventuraram por este planalto montanhoso, noutro, portugueses se aventuravam pela costa paulista, carioca e pernambucana. Diferenciam-se, portanto, pelo fato de que foi o cenário geológico que a preparou, aqueles blocos orogênicos e mineralizados que custearam não apenas o crescimento econômico de Portugal, mas o da Colônia, e, indiretamente, também, os próprios sentimentos de liberdade e independência. Nesse império de ouro, nota-se desajustadas medidas portuguesas ao desenvolvimento coeso das cidades e da população mineira. Interesses desencontrados pela corrida aurífera. Vê-se extravasar a riqueza das Minas para o mundo. Há até autor que aponte a influência decisiva de Minas na Revolução Industrial (AMARAL, 2012), ou ainda, que sem a entrada do ouro de Minas na Inglaterra, impossível seria enfrentar Napoleão (GALEANO, 1976, p.67). São 300 anos de muita história, mais do que o café ou o ouro. É o orgulho do mineiro, à sua maneira, deque tanto cantam os poetas e enredam os autores. O ouro era a riqueza das Minas Gerais, riqueza encaminhada para a Europa. Talvez por isto reclamem tanto os autores de uma independência para lá de política.

\section{REFERÊNCIAS}

ALKIMIN, Fernando F. História Geológica de Minas Gerais. Departamento de Geologia, Escola de Minas, Universidade Federal de Ouro Preto, 2018.

AMARAL, Alex Lombello. Origens das Minas Gerais. Minas Gerais: Heráclito, 2012.

BERGAD, Laird W. Slavery and the Demographic and Economic History of Minas

Gerais, Brazil, 1720-1888. São Paulo: CAMBRIDGE LATIN AMERICAN STUDIES, 1999.

BOCAYUVA, Quintino, 1836-1912. Os Mineiros da Desgraça. Rio de Janeiro: Typographia do Diario do Rio de Janeiro, 1862. Disponível em:

http://www2.senado.leg.br/bdsf/handle/id/242744. Acesso em: 15 de outubro de 2020.

CARPEAUX, Otto Maria. O Modernismo por Carpeaux. Rio de Janeiro: Leya, 2012.

CHAVEZ, Edneila Rodrigues. Criação de vilas em Minas Gerais no início do regime monárquico. VARIA HISTORIA, nº 51, vol. 29, p.817-845, set/dez 2013.

COSTA, Cláudio Manuel da. Poema Vila Rica. Ouro Preto : Typ. do Universal, 1839. Disponível em: https://digital.bbm.usp.br/handle/bbm/4682. Acesso em: 22 de setembro de 2020. 
CUNHA, Euclides da. Os Sertões. São Paulo: Três, 1984.

MINAS GERAIS. Decreto 36, DE 12/04/1890. Disponível em:

https://www.almg.gov.br/consulte/legislacao/completa/completa.html?tipo=DEC\&nu $\mathrm{m}=36 \&$ comp $=\& a n o=1890$. Acesso em: 22 de setembro de 2020 .

DORIA, Pedro. 1789: a história de Tiradentes, contrabandistas, assassinos e poetas que sonharam a Independência do Brasil. Rio de Janeiro: Nova Fronteira, 2013.

EDNA, Mara Ferreira da. A Ação da Justiça e a as Transgressões da Moral Processoscrime em Mariana - 1747-1830. Juiz de Fora: Laboratório de História Econômica e Social, da Universidade Federal de Juiz de Fora, 2005.

GALEANO, Eduardo. As Veias Abertas da América Latina. 14ª edição. Rio de Janeiro: Paz e Terra, 1976.

GERAIS, Estado de Minas. História. Disponível em: https://www.mg.gov.br/conhecaminas/folclore. Acesso em 20 de setembro de 2020.

GONZAGA, Tomáz Antônio. Cartas Chilenas. Disponível em:

http://www.dominiopublico.gov.br/pesquisa/DetalheObraForm.do?select_action=\&c o_obra=2011. Acesso em: 20 de setembro de 2020.

MINAS GERAIS. Lei no 302, DE 1 de julho de 1901. Disponível em: https://www.lexml.gov.br/urn/urn:lex:br;minas.gerais:estadual:lei:1901-07-01;302. Acesso em: 22 de setembro de 2020 .

LOBATO, Lydia Maria. Recursos Minerais no cenário geológico de Minas Gerais. Departamento de Geologia, Escola de Minas, Universidade Federal de Ouro Preto, 2018. MAXWELL, Kenneth. A Devassa da Devassa - Inconfidência Mineira; Brasil E Portugal, 1750-1808. São Paulo: Cambridge University Press, 1973.

MEIRELES, Cecília. Romanceiro da Inconfidência. Rio de Janeiro: Nova Aguiar S/A, 1977.

PITTA, Sebastião da Rocha. História da América Portuguesa. Bahia: Imprensa Econômica, 1878.

QUEIRÓS, B. Q. A literatura como atividade política. Revista Palavra SESC. RJ. N³ ano 4. Págs 21-35 julho de 2012.

QUINTÃO, José Maria. Aquibadam, ponte e vau: no ontem e o no hoje de ferros. Belo Horizonte: I. Oficial, 1985

RODRIGUES, Roberto Geraldo. Uma viagem pela poética de Carlos Drummond de Andrade, (Re)Tratando a marcante presença de Itabira em sua obra. 2011. 205 f. Tese (Doutorado em Letras). Vitória: Universidade Federal do Espírito Santo, 2011.

ROMEIRO, Adriana. A construção de um mito: Antônio de Albuquerque e olevante emboaba. Tempo, Niterói, v. 15, n. 29, p. 167-188, Dec. 2010 .Available from 
http://www.scielo.br/scielo.php?script=sci_arttext\&pid=S1413$77042010000200007 \& \operatorname{lng}=$ en\&nrm=iso. access on 22 Sept. 2020. https://doi.org/10.1590/S1413-77042010000200007.

SAINT-HILAIRE, Augusto de. Viagem pelas províncias do Rio de Janeiro e de Minas Geraes. Companhia Editora Nacional, 1938.

VASCONCELOS, Diogo de. História Antiga das Minas Geraes. Bello Horizonte: Imprensa Official do Estado de Minas Geraes, 1904.

VÁZQUEZ, A. S. Ética. Rio de Janeiro: Civilização Brasileira, 2007.

VERGUEIRO, Laura. Opulência e miséria das Minas Gerais. São Paulo: Brasiliense, 1981. 